\title{
Observed Changes in the Southern Hemispheric Circulation in May $\mathscr{a}$
}

\author{
Diane J. Ivy,${ }^{\mathrm{a}}$ CASEy Hilgenbrink, ${ }^{\mathrm{b}}$ Doug Kinnison, ${ }^{\mathrm{c}}$ R. Alan Plumb, ${ }^{\mathrm{a}}$ \\ ADITI SHESHADRI, ${ }^{\mathrm{d}}$ SUSAN SOLOMON, ${ }^{\mathrm{a}}$ AND DAVID W. J. THOMPSON ${ }^{\mathrm{e}}$ \\ ${ }^{a}$ Department of Earth, Atmospheric and Planetary Sciences, Massachusetts Institute of Technology, \\ Cambridge, Massachusetts \\ ${ }^{\mathrm{b}}$ Department of Atmospheric Sciences, University of Washington, Seattle, Washington \\ ${ }^{\mathrm{c}}$ National Center for Atmospheric Research, Boulder, Colorado \\ ${ }^{\mathrm{d}}$ Department of Applied Physics and Applied Mathematics, Columbia University, \\ New York, New York \\ ${ }^{\mathrm{e}}$ Department of Atmospheric Science, Colorado State University, \\ Fort Collins, Colorado
}

(Manuscript received 20 May 2016, in final form 20 September 2016)

\begin{abstract}
Much research has focused on trends in the Southern Hemispheric circulation in austral summer (December-February) in the troposphere and stratosphere, whereas changes in other seasons have received less attention. Here the seasonality and structure of observed changes in tropospheric and stratospheric winds, temperature, and ozone over the Southern Hemisphere are examined. It is found that statistically significant trends similar to those of the Antarctic summer season are also observed since 1979 in austral fall, particularly May, and are strongest over the Pacific sector of the hemisphere. Evidence is provided for a significant shift in the position of the jet in May over the Pacific, and it is shown that the strengthening and shifting of the jet has rendered the latitudinal distribution of upper-tropospheric zonal wind more bimodal. The Antarctic ozone hole has cooled the lower stratosphere and strengthened the polar vortex. While the mechanism and timing are not fully understood, the ozone hole has been identified as a key driver of the summer season tropospheric circulation changes in several previous observational and modeling studies. It is found here that significant ozone depletion and associated polar cooling also occur in the lowermost stratosphere and tropopause region through austral fall, with spatial patterns that are coincident with the observed changes in stratospheric circulation. It is also shown that radiatively driven temperature changes associated with the observed ozone depletion in May represent a substantial portion of the observed May cooling in the lowermost stratosphere, suggesting a potential for contribution to the circulation changes.
\end{abstract}

\section{Introduction}

Atmospheric circulation patterns play important roles in modulating Earth's climate. Evidence from a wide range of atmospheric observations shows that the Southern Hemispheric circulation has displayed substantial trends since the mid-twentieth century [see, e.g., the reviews by Russell and McGregor (2010) and

Supplemental information related to this paper is available at the Journals Online website: http://dx.doi.org/10.1175/JCLI-D-160394.s1.

Corresponding author address: Diane Ivy, Massachusetts Institute of Technology, 77 Massachusetts Ave., 54-1710, Cambridge, MA 02139.

E-mail: divy@mit.edu
Thompson et al. (2011) and references therein]. Most studies have focused on the Antarctic summer season, in which changes in the strength of the southern annular mode (SAM) since the 1980s have been linked mainly to the development of the Antarctic ozone hole using both observations and models (Thompson and Solomon 2002; Gillett and Thompson 2003; Son et al. 2009; Polvani et al. 2011), although there is evidence for a contribution from greenhouse gas changes as well (e.g., Fyfe et al. 1999; Kushner et al. 2001; Marshall et al. 2004; Arblaster and Meehl 2006; Lee and Feldstein 2013). Changes in other measures of the circulation, such as the strength or position of the westerly jet and the width of the Hadley cell, are well documented in austral summer (Son et al. 2009; Thompson et al. 2011; Thomas et al. 2015).

Marshall (2007) noted that a strong positive trend in the SAM also occurred in austral fall and argued that the 
fall trend was even stronger than the more widely studied summer SAM trend. Furthermore, Schneider et al. (2015) found that the westerly wind trends at $850 \mathrm{hPa}$ were 3 times stronger over the Pacific on an annual basis and in autumn compared to the zonal-mean wind trends, suggesting that the SAM, which shows less zonal variability, does not capture the strongest changes in the Southern Hemispheric circulation. A number of modeling studies have also presented evidence for long-term changes in other seasons, including austral fall (Kushner et al. 2001; McLandress et al. 2011; Bracegirdle et al. 2014). In analysis of the archive for phase 3 of the Coupled Model Intercomparison Project (CMIP3), Fogt et al. (2009) found a positive trend in the autumn SAM and noted that the magnitude of the trend was similar between models that did and did not include ozone depletion, suggesting that the autumn trends in the CMIP3 models were not driven by ozone. However, overall the modeled trends from CMIP3 were smaller than historical observations. Models in phase 5 of the Coupled Model Intercomparison Project (CMIP5) also showed a positive, although not statistically significant, trend in the autumn SAM, but analysis of single forcing simulations suggested contributions from greenhouse gases and ozone-depleting substances (IPCC 2013). A more recent study by Swart et al. (2015) compared seasonal trends in the SAM and surface westerlies from observations to the CMIP5 model simulations and also found a positive trend in the austral fall SAM and jet strength but no trend in jet position. Last we note that, unlike for well-mixed radiative forcing agents, such as carbon dioxide, there are substantial differences between different ozone datasets prescribed in climate model simulations (Hassler et al. 2013), and it cannot be assumed that the representation of ozone losses used in all models is accurate.

This study focuses on observed changes in the Antarctic circulation in austral fall, particularly the location of the westerly wind jet, as well as the vertical structure of related changes in zonal winds and temperature, and ozone as the possible driver. There are significant uncertainties as well as documented errors in available reanalyses in the Antarctic, particularly in the era before satellite coverage began (e.g., Bromwich et al. 2007; Bracegirdle and Marshall 2012). Thus, we compare results from multiple reanalyses. In austral fall, the jet is predominately over the Pacific and we compare the changes in the zonal mean, representative of the SAM, to those over the Pacific, further clarifying shifts in the position of the jet in May. However, we find that the changes in austral fall circulation are not statistically significant in March and April and are predominantly driven by the observed changes in May.

While there is strong evidence not only for stratospheric circulation changes but also for stratospheric- tropospheric coupling in January, the dynamical mechanisms and timing of the latter are not understood (Gerber et al. 2012). While the tropospheric response in austral summer lags the stratospheric response by 1-2 months (Previdi and Polvani 2014), theory to date has not yet fully explained the mechanisms for the onset of January coupling or its cessation in February, March, and April (Kushner and Polvani 2006). Here we do not attempt a comprehensive theory to explain these longstanding mysteries or the timing of the trends documented here in May. Rather we aim to document observations that may help to provide clues as to potential mechanisms. We show how the distributions of winds versus latitude in May are affected by both the subtropical and polar eddy-driven jets, resulting in a bimodal spatial structure that complicates the analysis at some pressure levels. Last, we find that historical changes in Antarctic ozone in May are significant, particularly in the lowermost stratosphere close to the tropopause. We show that this depletion leads to a contribution to cooling of lower-stratospheric temperatures, which can be expected to cause changes in the stratospheric circulation.

\section{Methods}

\section{a. Data}

Three reanalysis datasets, along with direct satellite measurements, were used to evaluate changes in Southern Hemispheric climate since the satellite era began in 1979. Evaluating multiple data sources provides an estimate of possible observational uncertainty and improves confidence in results that are statistically significant in all of the datasets. The historical differences in zonal wind and temperature are from monthlymean reanalyses data from the European Centre for Medium-Range Weather Forecasts (ECMWF) interim reanalysis (ERA-Interim; Dee et al. 2011), the ModernEra Retrospective Analysis for Research and Applications (MERRA; Rienecker et al. 2011), and the National Centers for Environmental PredictionNational Center for Atmospheric Research (NCEPNCAR) reanalysis (Kalnay et al. 1996). For the analysis of jet latitude position, daily data were also used. Additional lower-stratospheric temperature data are from the National Oceanic and Atmospheric Administration (NOAA) Center for Satellite Applications and Research (STAR) Microwave Sounding Unit (MSU; Zou et al. 2009), which samples the lower stratosphere. Vertically resolved ozone mixing ratio data are from the World Ozone and Ultraviolet Radiation Data Centre (WOUDC; www.woudc.org) archive for the ozonesonde station at Syowa, Antarctica $\left(69^{\circ} \mathrm{S}, 40^{\circ} \mathrm{E}\right)$, and 
from NOAA (www.esrl.noaa.gov/gmd/obop/spo/) for the ozonesonde station at South Pole, Antarctica $\left(90^{\circ} \mathrm{S}\right)$. Total column ozone measurements are from the $\mathrm{Na}$ tional Aeronautics and Space Administration's Total Ozone Mapping Spectrometer and Ozone Monitoring Instrument (TOMS/OMI, version 8; ozoneaq.gsfc.nasa. gov).

\section{b. PORT simulations}

The radiatively adjusted temperature changes attributable to the observed changes in ozone were estimated using the Parallel Offline Radiative Transfer (PORT) model (Conley et al. 2013). PORT utilizes the radiation code from NCAR's Community Atmosphere Model, version 4 (CAM4; Gent et al. 2011), and calculates the changes in radiatively adjusted temperatures in a seasonally evolving fixed dynamical heating calculation above a defined masked level (typically defined as the tropopause, but here set to $500 \mathrm{hPa}$ to allow the temperatures to adjust into the upper troposphere); the methodology is similar to that in Ivy et al. (2016). For the PORT calculation, a full three-dimensional ozone climatology was used to prescribe a predepletion background distribution. The background was based on the ensemble mean of four historical simulations from 1979 to 1985 using the Whole Atmosphere Community Climate Model (WACCM), version 3, as described in Garcia et al. (2007). To represent the ozone depletion at Syowa, the observed historical differences, taken as the differences between the later period (1995-2010) and an earlier period (1970-82), in vertically resolved ozone from Syowa were added to the 1979-85 background WACCM climatology and applied at all longitudes and latitudes from $60^{\circ} \mathrm{S}$ to the pole. The concentrations of well-mixed greenhouse gases were fixed at their 1979 values.

\section{c. Analysis}

The measure of long-term changes in Southern Hemispheric climate and circulation was taken as the difference between an early historical period (1979-85) and a later historical period (1995-2010) for the reanalyses. Because of limited ozone data availability (especially prior to the mid-1980s) the periods $1970-82$ and 1962-94 were used for the early historical periods in ozone data at Syowa and South Pole, respectively, whereas the later historical period for both was 19952010, as in the reanalysis. For the long-term changes in monthly-mean data, statistical significance was determined at the $95 \%$ level by a one-tailed Student's $t$ statistic (as in Santer et al. 2000); the results were robust when a 1-yr lag autocorrelation was also taken into account. Increasing well-mixed greenhouse gases and ozone depletion both affect stratospheric temperatures and are expected to produce a poleward shift of the jet (Thompson et al. 2011), motivating the usage of a onesided $t$ test.

Sudden stratospheric warmings have the potential to influence stratospheric ozone through warmer temperatures, resulting in less heterogeneous ozone depletion and increased downward transport of ozone-rich air (e.g., Siegmund et al. 2005). In late September 2002, the Antarctic underwent its first recorded major sudden stratospheric warming event (Baldwin et al. 2003). Hence, the 12-month period following the onset of this major sudden stratospheric warming (from September 2002 to August 2003) was removed in this analysis.

The jet position was evaluated using daily reanalysis data. From the reanalysis data, a cubic spline was fit to the zonally averaged zonal winds at a chosen pressure level, and the position of the jet was identified as the latitude at which the cubic spline interpolant reached an absolute maximum. However in austral fall, the subtropical jet in the upper troposphere begins to develop over the Indian Ocean, Australia, and the Pacific Ocean (Bals-Elsholz et al. 2001; Williams et al. 2007). Therefore, we also evaluated the jet position over the Pacific $\left(70^{\circ}-160^{\circ} \mathrm{W}\right)$ and compare the results with the jet position estimated from zonal-mean zonal winds.

\section{Results}

\section{a. Observed trends}

Figure 1 shows the seasonal differences in midlatitude $\left(50^{\circ}-70^{\circ} \mathrm{S}\right)$ zonal winds over the past 30 years averaged over the zonal-mean and Pacific sector $\left(70^{\circ}-160^{\circ} \mathrm{W}\right)$ from ERA-Interim, MERRA, and NCEP-NCAR reanalysis. As has been widely noted, there is a significant strengthening of the polar jet in December and January that extends from the lower stratosphere throughout the depth of the troposphere. However, an additional significant increase in the midlatitude zonal winds is also apparent in May in all three reanalysis datasets (albeit with some differences in magnitude); February and March do not display wind changes like those of January and May. Furthermore, the increase in May zonal wind is stronger when averaged over the Pacific sector of the Southern Hemisphere, as noted in Fogt et al. (2009) and seen in Fig. 1 (bottom). The anomalous winds in May over the Pacific extend from the surface into the lower stratosphere, mirroring the behavior seen in January, but have not been previously highlighted. We note that January and May are the only months where a statistically significant change in the midlatitude winds is observed in both the stratosphere and troposphere. 
U (50-70 ०) S Differences [m/s]: (1995-2010) - (1979-1985)
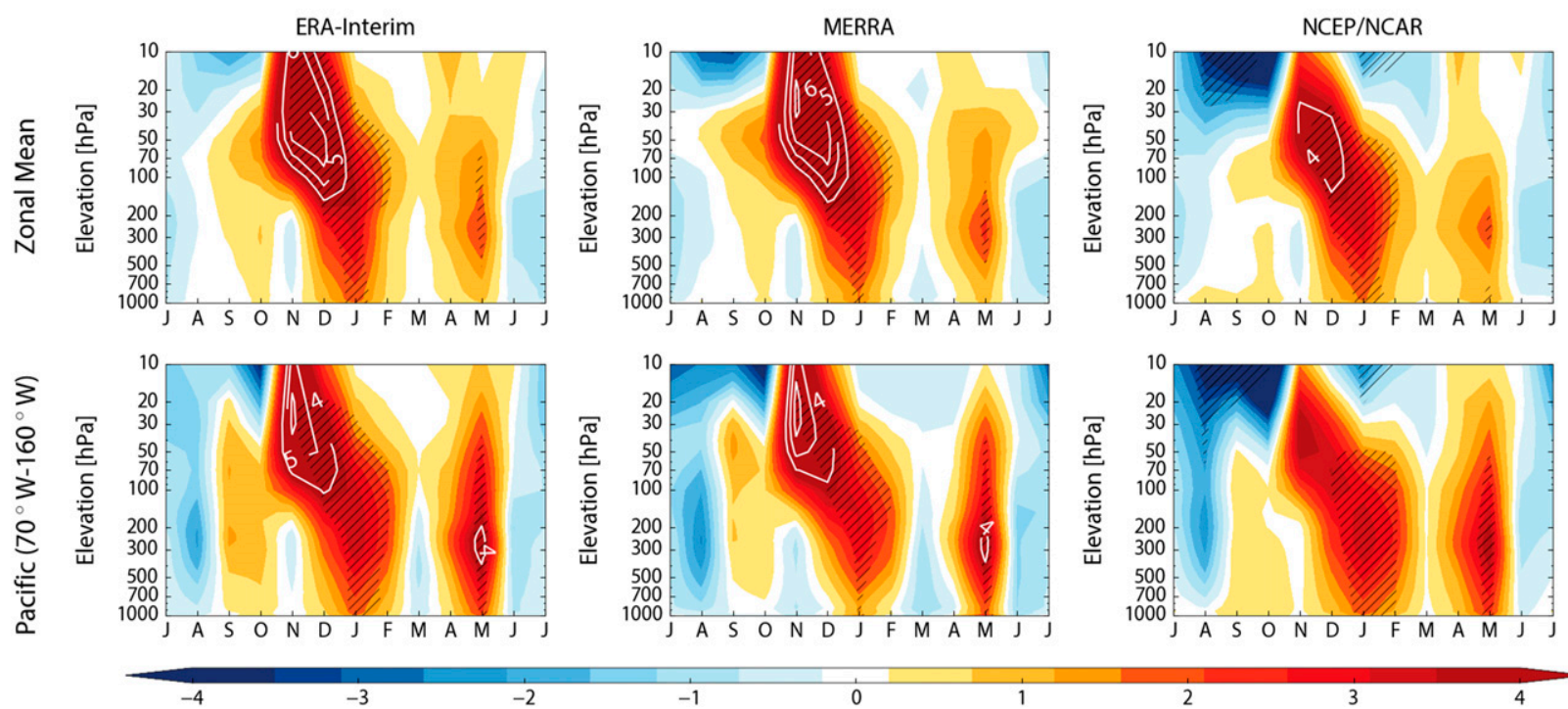

$$
-2
$$

$-1 \quad 0$

2

3

4

FIG. 1. Seasonal differences between the early (1979-85) and late period (1995-2010) midlatitude (50 $\left.-70^{\circ} \mathrm{S}\right)$ zonal winds averaged over the (top) zonal mean and (bottom) Pacific sector $\left(70^{\circ}-160^{\circ} \mathrm{W}\right)$ from ERA-Interim, MERRA, and NCEP-NCAR reanalysis. Hatching denotes differences that are statistically significant at the $95 \%$ level and the white contours are every $1 \mathrm{~m} \mathrm{~s}^{-1}$, beginning at $4 \mathrm{~m} \mathrm{~s}^{-1}$.

Figure 1 also indicates easterly trends between $50^{\circ}$ and $70^{\circ} \mathrm{S}$ during June-August in the stratosphere, but the tropospheric trends in these months are not statistically significant and not further discussed here.
Figure 2 shows histograms of the daily jet position in January and May for the early and late historical periods for ERA-Interim as an example (Fig. S1 in the supplemental material shows similar histograms for MERRA a) ERA-Interim Jet Latitudes (Zonal-Mean Zonal Wind)
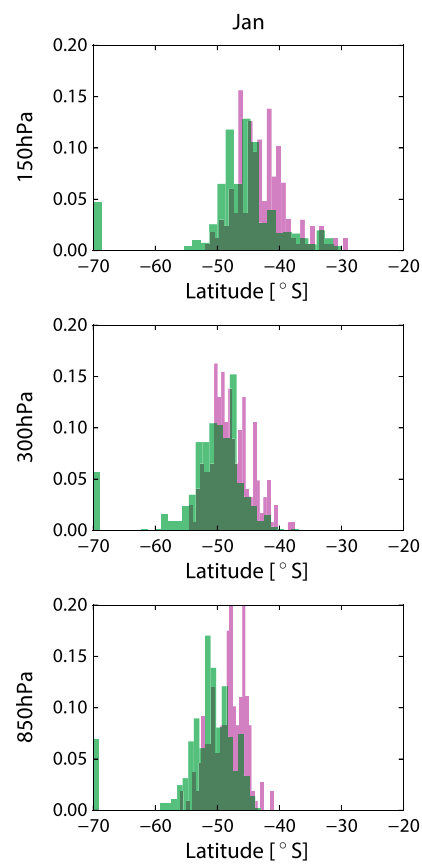

May
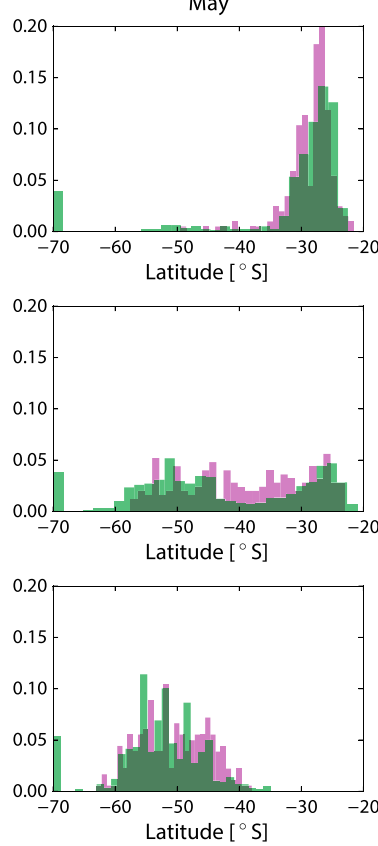

b) ERA-Interim Jet Latitudes (Pacific Zonal Wind)
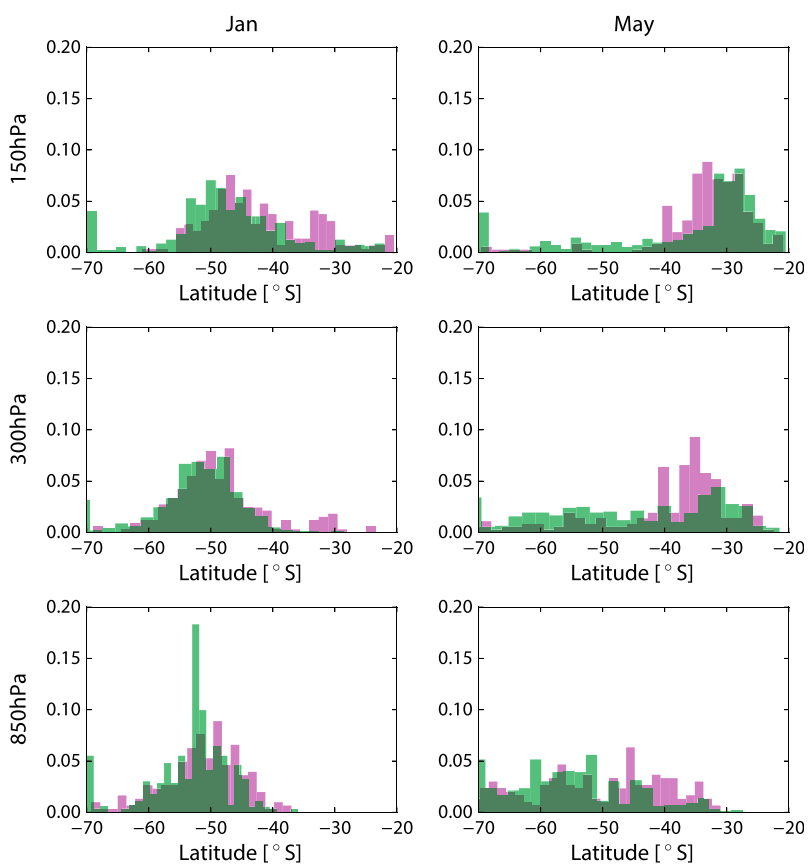

FIG. 2. Histograms of daily jet latitudes based on zonal winds averaged over the (a) zonal mean and (b) Pacific sector in January and May at 150,300 , and $850 \mathrm{hPa}$ between the early (1979-85; purple) and late period (1995-2010; green) from ERA-Interim. 
a) Monthly Mean Zonal-Mean Zonal Wind
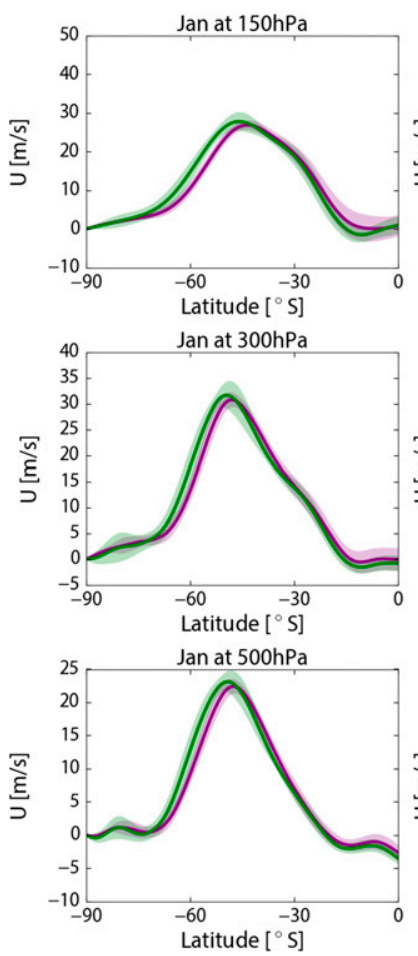
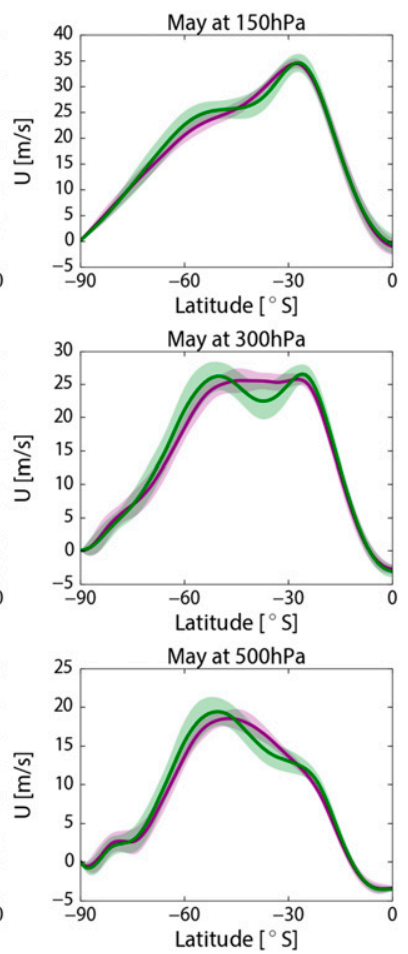

b) Monthly Mean Pacific Zonal Wind
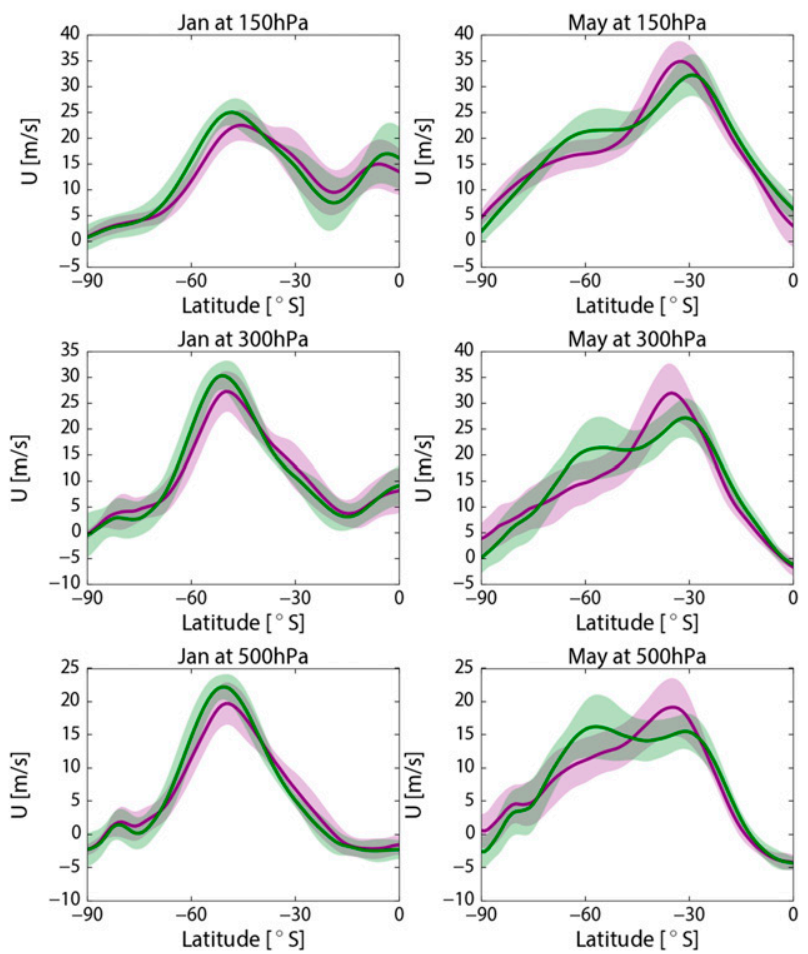

FIG. 3. Monthly-mean zonal winds by latitude averaged over the (a) zonal mean and (b) Pacific sector in January and May at 150, 300, and $500 \mathrm{hPa}$ for the early (1979-85; purple) and late period (1995-2010; green) from ERA-Interim. The shading denotes one std dev of the monthly-mean January or May zonal wind for each period at each latitude.

and NCEP-NCAR reanalysis). The strengthening of the zonal mean and Pacific sector midlatitude zonal winds is associated with a poleward shift of the jet in December (not shown) and January. In the zonal mean there is no clear shift of the polar jet in May. However, over the Pacific sector the jet is found more frequently over the midlatitudes $\left(45^{\circ}-70^{\circ} \mathrm{S}\right)$ during the ozone hole era than over the subtropics in the early period ( $44 \%$ compared to $21 \%$ of the time at $500 \mathrm{hPa}$, respectively), suggesting the emergence of a stronger bimodal spatial character in the May zonal wind distribution over the Pacific in the last decade.

The shift to a more bimodal distribution of the jet over the Pacific sector in May is also observed in the strength of the jet. Figure 3 presents the latitudinal distributions of the monthly-mean zonal-mean and Pacific sector zonal winds for January and May from ERA-Interim at 150, 300, and $500 \mathrm{hPa}$. The tropospheric and lowerstratospheric polar jets have strengthened and shifted poleward in January over the last three decades. The zonal winds have also strengthened over the midlatitudes in May, particularly over the Pacific sector peaking at $46^{\circ} \mathrm{S}$ and a speed of $14.6 \pm 3.3 \mathrm{~m} \mathrm{~s}^{-1}$ in the early period compared to $55^{\circ} \mathrm{S}$ at a speed of $16.2 \pm$ $4.8 \mathrm{~m} \mathrm{~s}^{-1}$ in the later period. These results also suggest that the zonal wind distribution has developed a distinct bimodal spatial character in May over the last decade.

\section{b. Possible role of ozone}

Figure 4 shows observed differences between the early and late periods in the latitude/longitude structure of total column ozone from TOMS, lower-stratospheric temperatures from MSU, and geopotential height at $150 \mathrm{hPa}$ and zonal winds at $300 \mathrm{hPa}$ from ERA-Interim (Fig. S2 in the supplemental material shows analogous differences for all of the reanalyses). In May, total column ozone has declined in the Southern Hemisphere over the past 30 years, and the region of strongest depletion over the midlatitudes peaks over the Pacific, coinciding with the strongest trends in zonal winds. Corresponding decreases in lower-stratospheric temperatures are also observed in the regions of ozone depletion. Furthermore, there are circulation changes in May over the Pacific, as seen in the differences in geopotential heights in the lower stratosphere, resembling a wave-3 pattern, and increased zonal winds in the upper troposphere. The observed differences in January (Fig. 4) mirror those in May, with decreases in ozone over the midlatitudes and a corresponding decrease in 
Differences (1995-2010) - (1979-1985)
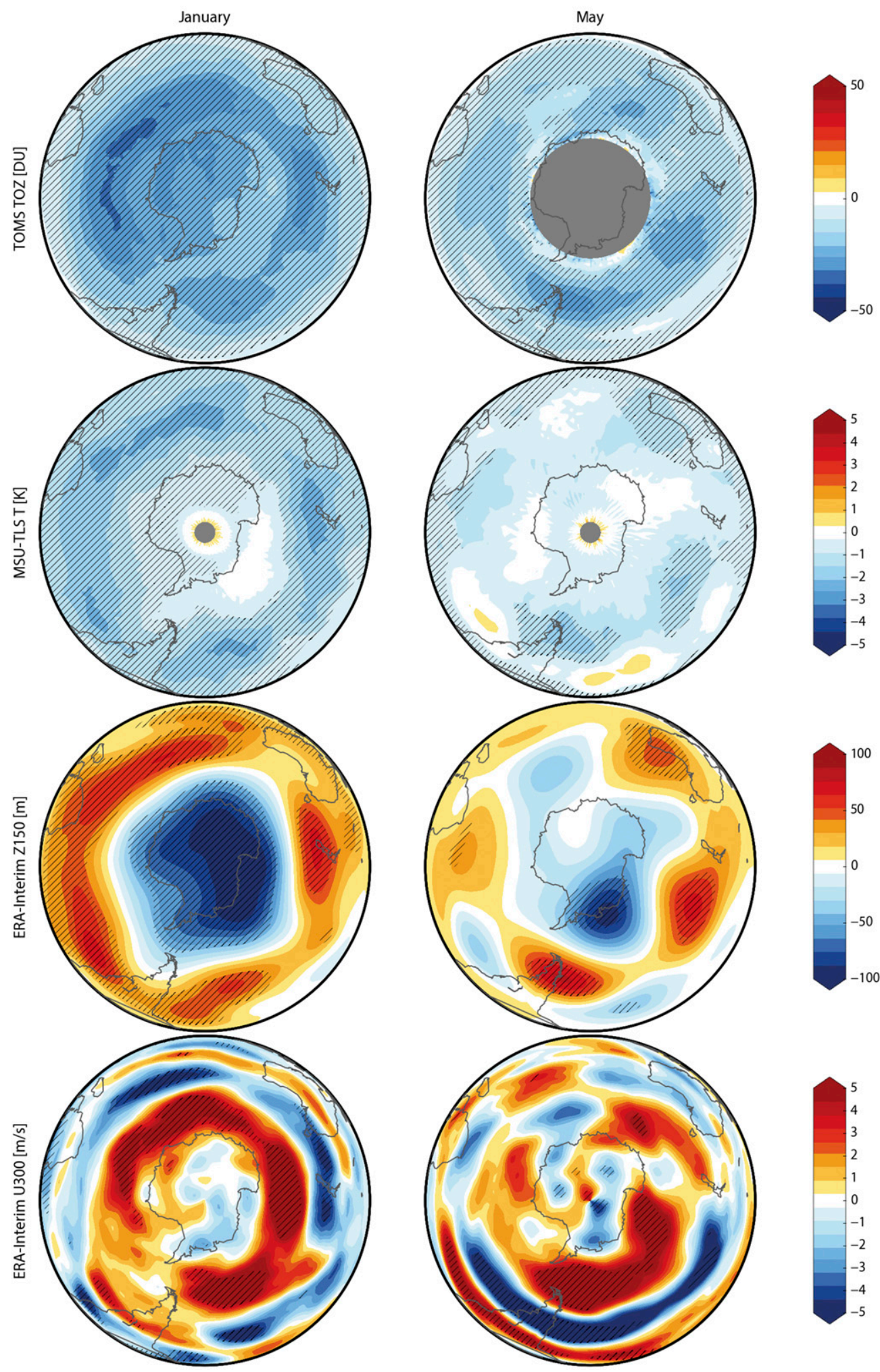

FIG. 4. Differences in the latitude/longitude structure between the early (1979-85) and late period (19952010) in January and May for total column ozone [Dobson units (DU)] from TOMS, lower-stratospheric temperatures (K) from MSU, geopotential height $(\mathrm{m})$ at $150 \mathrm{hPa}$ from ERA-Interim, and zonal wind $\left(\mathrm{m} \mathrm{s}^{-1}\right)$ at $300 \mathrm{hPa}$ from ERA-Interim. Hatching denotes differences that are statistically significant at the $95 \%$ level. 

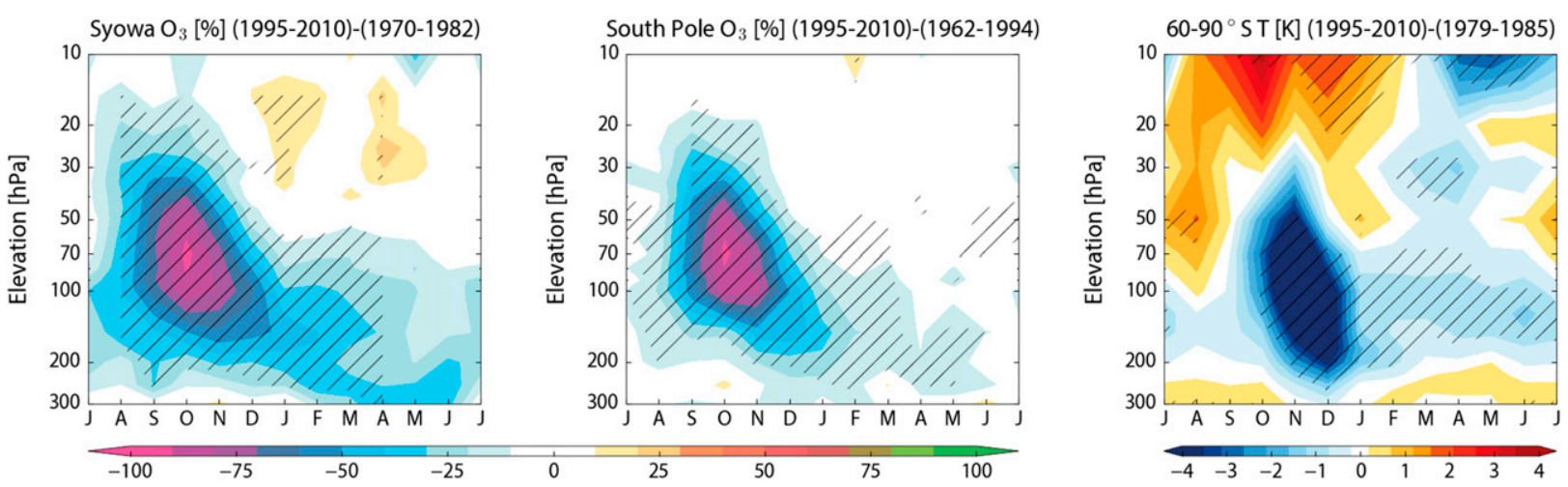

FIG. 5. Seasonal differences between the early (1970-82 for Syowa, 1962-94 for the South Pole, and 1979-85 for ERA-Interim) and late period (1995-2010) in ozone at Syowa $\left(69^{\circ} \mathrm{S}\right)$ and the South Pole $\left(90^{\circ} \mathrm{S}\right)$ and polar cap-averaged $\left(60^{\circ}-90^{\circ} \mathrm{S}\right)$ temperature from ERAInterim. Hatching denotes differences that are statistically significant at the $95 \%$ level.

lower-stratospheric temperatures and changes in the circulation, although they are more zonally symmetric.

The seasonal observed differences between the early and late periods in vertically resolved Antarctic ozone and temperature are shown in Fig. 5. While the strongest ozone depletion is observed in October, the ozone losses persist into January through May near the tropopause. As seen in the differences in total column ozone, the ozone losses in January and May are weaker over the pole and stronger near $60^{\circ} \mathrm{S}$, as also seen in the ozone differences at Syowa compared to the South Pole. There is an associated cooling throughout the lower stratosphere year-round, as seen in Fig. 5 (right).

Figure 6 shows the radiative temperature changes due to the observed ozone depletion at Syowa as estimated from PORT in January and May. The decreases in May ozone near the tropopause are comparable to those observed in January at Syowa. Moreover, the observed ozone changes lead to a radiative cooling, with a peak in the lowermost stratosphere of $0.8-1 \mathrm{~K}$ in both January and May. This radiatively driven cooling due to the observed ozone depletion extends throughout the lowermost stratosphere and into the uppermost troposphere (see also Grise et al. 2009). The observed temperature differences show a peak cooling of $1.7 \mathrm{~K}$ at $170 \mathrm{hPa}$ in January and $1.0 \mathrm{~K}$ at $120 \mathrm{hPa}$ in May. Based on our radiative calculations, approximately $60 \%-80 \%$ of the observed cooling can be attributed to the decline in ozone in both January and May. Hence the radiative impacts of stratospheric ozone depletion likely play a substantial role in the observed changes in the atmospheric circulation during May.

\section{Conclusions}

In this study, we have shown a statistically significant strengthening of observed midlatitude zonal winds in
May throughout the depth of the troposphere and lower stratosphere that is similar to the trends in austral summer. The strengthening of the May zonal winds is strongest over the Pacific sector of the hemisphere and coincides with a poleward shift of the extratropical jet. The poleward shift of the jet in May is qualitatively similar to that observed in December and January but the May change is notably different in that the trends in May lead to a bimodal spatial structure in the zonalmean flow.

The Antarctic ozone hole is believed to be the primary driver of the December and January cooling over the polar cap, which (through thermal wind balance) has strengthened the stratospheric jet and (through mechanisms not fully understood) has led to a poleward shift of the tropospheric jet. Our work provides new information on how ozone has also decreased in the lowermost stratosphere and tropopause region in May, and shows that there is an associated radiatively driven cooling that can be expected to cause changes in circulation in this season. Indeed, much of the observed cooling in the lower stratosphere can be attributed to radiative temperature changes associated with the observed ozone depletion in both January and May. Since the radiative cooling due to ozone extends into the uppermost troposphere (Grise et al. 2009), it is plausible that the stratospheric ozone anomalies induce a radiative cooling extending into the upper troposphere, and thus perturbing tropospheric dynamics and contributing to the zonal wind response in the troposphere.

Ozone depletion is also observed in late austral summer and early fall (February-April; not shown), but statistically significant changes in the circulation are not observed at this time. Future research is needed to understand why ozone depletion seemingly projects onto the tropospheric circulation in certain months but not in others. Based on simplified general circulation model 

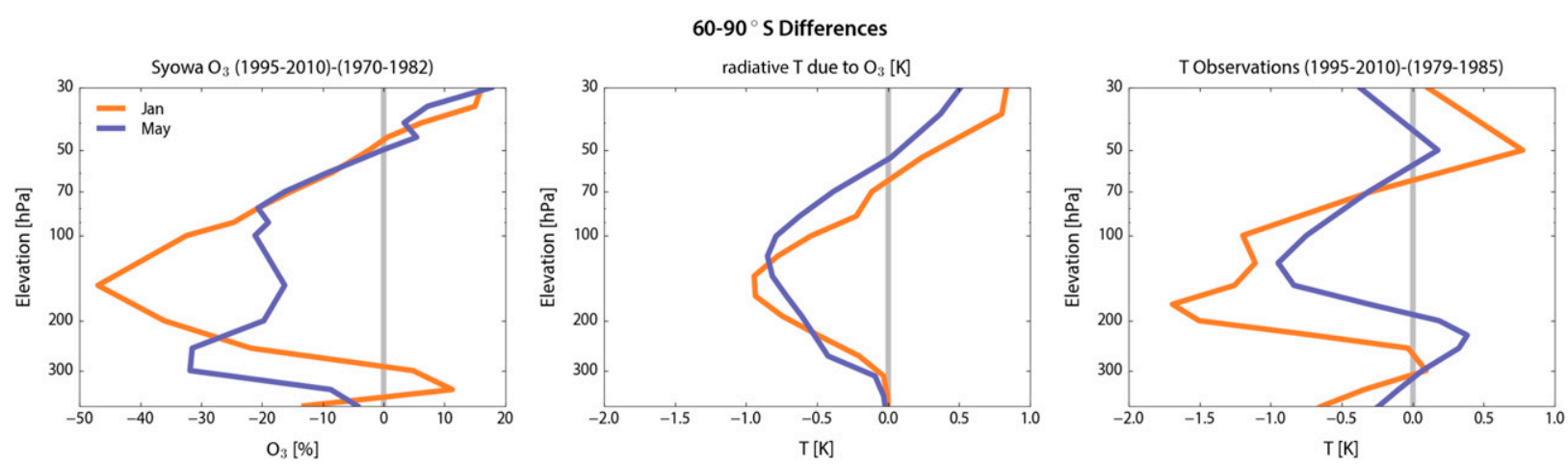

FIG. 6. Differences between the early (1970-82 for ozone at Syowa and 1979-85 for ERA-Interim temperature) and late period (1995$2010)$ for ozone from the WOUDC station Syowa $\left(69^{\circ} \mathrm{S}\right)$, and polar cap-averaged $\left(60^{\circ}-90^{\circ} \mathrm{S}\right)$ radiatively adjusted temperatures estimated from PORT, and observed temperatures from ERA-Interim in January and May.

simulations, Kushner and Polvani (2004) concluded that the interactions between tropospheric eddies and the mean state of the stratosphere were important for stratospheric-tropospheric coupling, while Gerber and Polvani (2009) noted the importance of planetary waves. A later study by Kushner and Polvani (2006) found in model simulations that the imposed seasonal cycle might be important in determining the onset of the tropospheric response time to an imposed stratospheric cooling, but does not explain its cessation. Thus, the mechanisms for stratospheric-tropospheric coupling and its seasonality are still an active area of research. Nevertheless, dynamical feedbacks are likely important in both January and May, particularly insofar as tropospheric responses are concerned (Kushner and Polvani 2004; Shaw et al. 2011).

Previous studies have analyzed seasonal trends in the SAM, while our results show the austral fall trends are strongest in May and over the Pacific region. Swart et al. (2015) found a seasonal (March-May) increasing trend in the SAM and jet speed but not the jet position. However Swart et al. (2015) assumed a spatially unimodal surface westerly jet. Zheng et al. (2015) noted a strong interseasonal relationship between the austral summer and fall SAM and proposed that the shifting of the surface westerlies associated with a positive summer SAM creates a dipole of SSTs over the Southern Ocean, which provides a seasonal memory into the fall. However, the imposed SST forcings in their Community Atmosphere Model, version 5 (CAM5), simulations that were necessary to produce a realistic meridional circulation response were larger than observations. Schneider et al. (2015) also observed a strengthening of the zonal winds in austral fall in the zonal mean and over the Pacific. However, we note that our findings suggest that the observed fall seasonal averaged trends are mainly driven by trends in May. Furthermore, their
CAM4 simulations with time-varying SSTs and ozone depletion, as specified from Stratosphere-Troposphere Processes and their Role in Climate (SPARC) and a historical WACCM simulation, also showed a change in the austral fall circulation. Schneider et al. (2015) concluded that the tropical SSTs were the main drivers via teleconnections of the autumn trends, based on the ensemble mean of all of the CAM4 simulations with ozone depletion not showing a strong forced response. However, unlike the sonde data shown here, the ozone depletion in the SPARC dataset shows negligible trends in the fall (Ivy et al. 2016) and thus would not be expected to show a forced response.

The observed historical changes in geopotential height in May resemble a wave-3 pattern (Fig. 4) and in particular show a decrease over the Amundsen Sea. Turner et al. (2009) found a strengthening of the Amundsen Sea low (ASL), and based on model simulations suggested it was driven by stratospheric ozone depletion. Furthermore, their atmospheric general circulation model simulations with stratospheric ozone depletion reveal midtropospheric circulation differences similar to the historical differences observed in May presented in this study. A later study by Turner et al. (2013) noted that the deepening of the ASL attributable to ozone depletion was unique to May, and that the ASL is influenced by both high-latitude and tropical forcings in March, whereas the ASL trend is weak in April. These results by Turner et al. $(2009,2013)$ suggest a role for stratospheric ozone depletion in altering the Southern Hemispheric tropospheric circulation in May.

Our analysis suggests that changes in atmospheric composition and temperatures may also contribute to the fall Southern Hemispheric circulation changes and are a significant driver of long-term temperature trends near the tropopause. The specific dynamical processes 
that couple such stratospheric perturbations to the troposphere remain a subject of much research (e.g., Gerber et al. 2012) and are not addressed in this study. Even in the summer months under large ozone forcing, it is evident that dynamical feedbacks are key to tropospheric circulation changes. The fact that tropospheric circulation changes occur in January and May but not in February and March, despite changes in ozone in all four months, attests to the importance of other processes, presumably dynamics related. Our work suggests that Antarctic ozone losses merit attention in the analysis and interpretation of recent Southern Hemisphere climate change not just in summer, but also in austral fall.

Acknowledgments. This research was supported by NSF Grant 1419667 to MIT. DWJT is support by the NSF Climate Dynamics Program. AS was funded by a Junior award from the Simons foundation.

\section{REFERENCES}

Arblaster, J. M., and G. A. Meehl, 2006: Contributions of external forcings to southern annular mode trends. J. Climate, 19, 28962905, doi:10.1175/JCLI3774.1.

Baldwin, M., T. Hirooka, A. O’Neill, and S. Yoden, 2003: Major stratospheric warming in the Southern Hemisphere in 2002: Dynamical aspects of the ozone hole split. SPARC Newsletter, No. 20, SPARC Office, Zurich, Switzerland, 24-26. [Available online at http://www.sparc-climate.org/fileadmin/customer/6_ Publications/Newsletter_PDF/20_SPARCnewsletter_Jan2003_ redFile.pdf.]

Bals-Elsholz, T. M., E. H. Atallah, L. F. Bosart, T. A. Wasula, M. J. Cempa, and A. R. Lupo, 2001: The wintertime Southern Hemisphere split jet: Structure, variability, and evolution. J. Climate, 14, 4191-4215, doi:10.1175/1520-0442(2001)014<4191: TWSHSJ $>2.0 . \mathrm{CO} ; 2$.

Bracegirdle, T. J., and G. J. Marshall, 2012: The reliability of Antarctic tropospheric pressure and temperature in the latest global reanalyses. J. Climate, 25, 7138-7146, doi:10.1175/ JCLI-D-11-00685.1.

_ - J. Turner, J. S. Hosking, and T. Phillips, 2014: Sources of uncertainty in projections of twenty-first century westerly wind changes over the Amundsen Sea, West Antarctica, in CMIP5 climate models. Climate Dyn., 43, 2093-2104, doi:10.1007/s00382-013-2032-1.

Bromwich, D. H., R. L. Fogt, K. I. Hodges, and J. E. Walsh, 2007: A tropospheric assessment of the ERA-40, NCEP, and JRA-25 global reanalyses in the polar regions. J. Geophys. Res., 112, D10111, doi:10.1029/2006JD007859.

Conley, A. J., J.-F. Lamarque, F. Vitt, W. D. Collins, and J. Kiehl, 2013: PORT, a CESM tool for the diagnosis of radiative forcing. Geosci. Model Dev., 6, 469-476, doi:10.5194/ gmd-6-469-2013.

Dee, D. P., and Coauthors, 2011: The ERA-Interim reanalysis: Configuration and performance of the data assimilation system. Quart. J. Roy. Meteor. Soc., 137, 553-597, doi:10.1002/qj.828.

Fogt, R. L., J. Perlwitz, A. J. Monaghan, D. H. Bromwich, J. M. Jones, and G. J. Marshall, 2009: Historical SAM variability.
Part II: Twentieth-century variability and trends from reconstructions, observations, and the IPCC AR4 models. J. Climate, 22, 5346-5365, doi:10.1175/2009JCLI2786.1.

Fyfe, J. C., G. J. Boer, and G. M. Flato, 1999: The Arctic and Antarctic Oscillations and their projected changes under global warming. Geophys. Res. Lett., 26, 1601-1604, doi:10.1029/ 1999GL900317.

Garcia, R. R., D. R. Marsh, D. E. Kinnison, B. A. Boville, and F. Sassi, 2007: Simulation of secular trends in the middle atmosphere, 1950-2003. J. Geophys. Res., 112, D09301, doi:10.1029/ 2006JD007485.

Gent, P. R., and Coauthors, 2011: The Community Climate System Model version 4. J. Climate, 24, 4973-4491, doi:10.1175/ 2011JCLI4083.1.

Gerber, E. P., and L. M. Polvani, 2009: Stratosphere-troposphere coupling in a relatively simple AGCM: The importance of stratospheric variability. J. Climate, 22, 1920-1933, doi:10.1175/ 2008JCLI2548.1

— , and Coauthors, 2012: Assessing and understanding the impact of stratospheric dynamics and variability on the Earth system. Bull. Amer. Meteor. Soc., 93, 845-859, doi:10.1175/ BAMS-D-11-00145.1.

Gillett, N. P., and D. W. J. Thompson, 2003: Simulation of recent Southern Hemisphere climate change. Science, 302, 273-275, doi:10.1126/science.1087440.

Grise, K. M., D. W. J. Thompson, and P. M. Forster, 2009: On the role of radiative processes in stratosphere-troposphere coupling. J. Climate, 22, 4154-4161, doi:10.1175/2009JCLI2756.1.

Hassler, B., P. J. Young, R. W. Portmann, G. E. Bodeker, J. S. Daniel, K. H. Rosenlof, and S. Solomon, 2013: Comparison of three vertically resolved ozone data sets: Climatology, trends and radiative forcings. Atmos. Chem. Phys., 13, 5533-5550, doi:10.5194/acp-13-5533-2013.

IPCC, 2013: Climate Change 2013: The Physical Science Basis. Cambridge University Press, 1535 pp., doi:10.1017/ CBO9781107415324.

Ivy, D. J., S. Solomon, and H. E. Rieder, 2016: Radiative and dynamical influences on polar stratospheric temperature trends. J. Climate, 29, 4927-4938, doi:10.1175/JCLI-D-15-0503.1.

Kalnay, E., and Coauthors, 1996: The NCEP/NCAR 40-Year Reanalysis Project. Bull. Amer. Meteor. Soc., 77, 437-471, doi:10.1175/1520-0477(1996)077<0437:TNYRP>2.0.CO;2.

Kushner, P. J., and L. M. Polvani, 2004: Stratosphere-troposphere coupling in a relatively simple AGCM: The role of eddies. J. Climate, 17, 629-639, doi:10.1175/1520-0442(2004)017<0629: SCIARS $>2.0 . \mathrm{CO} ; 2$

$\longrightarrow$, and - 2006: Stratosphere-troposphere coupling in a relatively simple AGCM: Impact of the seasonal cycle. J. Climate, 19, 5721-5727, doi:10.1175/JCLI4007.1.

_ I. M. Held, and T. L. Delworth, 2001: Southern Hemisphere atmospheric circulation response to global warming. J. Climate, 14, 2238-2249, doi:10.1175/1520-0442(2001)014<0001: SHACRT $>2.0 . \mathrm{CO} ; 2$

Lee, S., and S. B. Feldstein, 2013: Detecting ozone- and greenhouse gas-driven wind trends with observational data. Science, $\mathbf{3 3 9}$, 563-567, doi:10.1126/science.1225154.

Marshall, G. J., 2007: Half-century seasonal relationships between the southern annular mode and Antarctic temperatures. Int. J. Climatol., 27, 373-383, doi:10.1002/joc.1407.

, P. A. Stott, J. Turner, W. M. Connolley, J. C. King, and T. A. Lachlan-Cope, 2004: Causes of exceptional atmospheric circulation changes in the Southern Hemisphere. Geophys. Res. Lett., 31, L14205, doi:10.1029/2004GL019952. 
McLandress, C., T. G. Shepherd, J. F. Scinocca, D. A. Plummer, M. Sigmond, A. I. Jonsson, and M. C. Reader, 2011: Separating the dynamical effects of climate change and ozone depletion. Part II: Southern Hemisphere troposphere. J. Climate, 24, 1850-1868, doi:10.1175/2010JCLI3958.1.

Polvani, L. M., D. W. Waugh, G. J. P. Correa, and S.-W. Son, 2011: Stratospheric ozone depletion: The main driver of twentieth-century atmospheric circulation changes in the Southern Hemisphere. J. Climate, 24, 795-812, doi:10.1175/ 2010JCLI3772.1.

Previdi, M., and L. M. Polvani, 2014: Climate system response to stratospheric ozone depletion and recovery. Quart. J. Roy. Meteor. Soc., 140, 2401-2419, doi:10.1002/qj.2330.

Rienecker, M. M., and Coauthors, 2011: MERRA: NASA's Modern-Era Retrospective Analysis for Research and Applications. J. Climate, 24, 3624-3648, doi:10.1175/ JCLI-D-11-00015.1.

Russell, A., and G. McGregor, 2010: Southern Hemisphere atmospheric circulation: Impacts on Antarctic climate and reconstructions from Antarctic ice core data. Climatic Change, 99, 155-192, doi:10.1007/s10584-009-9673-4.

Santer, B. D., T. M. L. Wigley, J. S. Boyle, D. J. Gaffen, J. J. Hnilo, D. Nychka, D. E. Parker, and K. E. Taylor, 2000: Statistical significance of trends and trend differences in layer-average atmospheric temperature time series. J. Geophys. Res., 105, 7337-7356, doi:10.1029/1999JD901105.

Schneider, D. P., C. Deser, and T. Fan, 2015: Comparing the impacts of tropical SST variability and polar stratospheric ozone loss on the Southern Ocean westerly winds. J. Climate, $\mathbf{2 8}$, 9350-9372, doi:10.1175/JCLI-D-15-0090.1.

Shaw, T. A., J. Perlwitz, N. Harnik, P. A. Newman, and S. Pawson, 2011: The impact of stratospheric ozone changes on downward wave coupling in the Southern Hemisphere. J. Climate, 24, 4210-4229, doi:10.1175/2011JCLI4170.1.

Siegmund, P., H. Eskes, and P. van Velthoven, 2005: Antarctic ozone transport and depletion in austral spring 2002. J. Atmos. Sci., 62, 838-847, doi:10.1175/JAS-3320.1.
Son, S.-W., N. F. Tandon, L. M. Polvani, and D. W. Waugh, 2009: Ozone hole and Southern Hemisphere climate change. Geophys. Res. Lett., 36, L15705, doi:10.1029/2009GL038671.

Swart, N. C., J. C. Fyfe, N. Gillett, and G. J. Marshall, 2015: Comparing trends in the southern annular mode and surface westerly jet. J. Climate, 28, 8840-8859, doi:10.1175/ JCLI-D-15-0334.1.

Thomas, J. L., D. W. Waugh, and A. Gnanadesikan, 2015: Southern Hemisphere extratropical circulation: Recent trends and natural variability. Geophys. Res. Lett., 42, 5508-5515, doi:10.1002/2015GL064521.

Thompson, D. W. J., and S. Solomon, 2002: Interpretation of recent Southern Hemisphere climate change. Science, 296, 895-899, doi:10.1126/science.1069270.

- - - P. J. Kushner, M. H. England, K. M. Grise, and D. J. Karoly, 2011: Signatures of the Antarctic ozone hole in Southern Hemisphere surface climate change. Nat. Geosci., 4, 741-749, doi:10.1038/ngeo1296.

Turner, J., and Coauthors, 2009: Non-annular atmospheric circulation change induced by stratospheric ozone depletion and its role in the recent increase of Antarctic sea ice extent. Geophys. Res. Lett., 36, L08502, doi:10.1029/2009GL037524.

_ T. Thillips, J. S. Hosking, G. J. Marshall, and A. Orr, 2013: The Amundsen Sea low. Int. J. Climatol., 33, 1818-1829, doi:10.1002/joc.3558.

Williams, L. N., S. Lee, and S.-W. Son, 2007: Dynamics of the Southern Hemisphere spiral jet. J. Atmos. Sci., 64, 548-563, doi:10.1175/JAS3939.1.

Zheng, F., J. Li, L. Wang, F. Xie, and X. Li, 2015: Cross-seasonal influence of the December-February Southern Hemisphere annular mode on March-May meridional circulation and precipitation. J. Climate, 28, 6859-6881, doi:10.1175/ JCLI-D-14-00515.1.

Zou, C.-Z., M. Gao, and M. D. Goldberg, 2009: Error structure and atmospheric temperature trends in observations from the Microwave Sounding Unit. J. Climate, 22, 1661-1681, doi:10.1175/2008JCLI2233.1. 